\title{
NUMERICAL MODELLING OF GLACIER RESPONSE TO A PERTURBATION IN THICKNESS
}

\author{
(Abstract only) \\ by \\ Keith Echelmeyer \\ (Division of Geology and Planetary Sciences, California Institute of Technology, Pasadena, \\ California 91125 , U.S.A.)
}

\begin{abstract}
Blue Glacier was subject to 5 to $10 \%$ increase in thickness during the period 1958 to 1978 . A surface velocity increase of 15 to $50 \%$ has accompanied this change in ice thickness. A non-uniform distribution of thickening over the glacier produced a general decrease in surface slope. The flow law parameters in a power-law relation for ice can be obtained from the resulting increase in velocity.

In 1957-58 the surface velocities and surface elevation along several transverse profiles were determined by others. During the period 1977 to 1980 similar measurements were made of surface velocity, elevation, and ice thickness along profiles spatialiy equivalent to those of the 1957-58 survey. Using these results a detailed study of the flow response has been made. Preliminary results indicate that the controlling surface slope $\alpha$ is one that is averaged over approximately ten times the glacier thickness and also indicate a relatively high stress exponent $n=4$ to 5 .
\end{abstract}

Blue Glacier flows in a complex channel and any detailed interpretation of the flow response requires the inclusion of this geometry in a model. For this reason multi-dimensional finite-element methods using a non-linear constitutive relation were employed. Various degrees of model sophistication allowed for the specification of different parameters governing the flow of the glacier. Variations in the flow law parameters and the curvature of the channel were found to have significant effects on the velocity and stress fields, as well as on the characteristics of the flow response to the thickness perturbation. Fully three-dimensional inodels of the flow of Blue Glacier and its response to the thickness increase were developed. Important effects such as those arising from longitudinal thickness and surface slope variations were included in three-dimensional modeling. The three-dimensional effects were seen to play an important role in flow of a rheologically non-linear fluid such as ice.

\section{MEASURING SNOW WATER EOUIVALENT BY COSMIC}

\author{
RADIATION
}

\section{(Abstract only)}

by

\section{W. Fritzsche*}

(Institut für Elektronik, Technische Universität Graz, Inffeldgasse 12, A-8010 Graz, Austria)

\section{ABSTRACT}

We have reduced the time taken for measurement of snow water equivalent using cosmic radiation by two to four hours with an accuracy of $1 \mathrm{~cm}$ of water equivalent. When $\mathrm{BF}_{3}$ counters were used by Kodama in 1975 , it took three days. For comparison we sometimes still have to make measurements manually or automatically in flat areas. These measurements can then be compared with measurements from avalanche starting zones where conditions can be quite different because of wind or ablation.

For avalanche forecasting, or in similar situations, when an accuracy of $1 \mathrm{~cm}$ is needed within a few hours, we suggest the use of scintillation counters with a doped plastic material. The greatest accuracy is obtained by using a separate site where values are recorded without snow. In this case 200000 pulses per hour are obtained (absorption length of $400 \mathrm{~cm}$ ) which after measurements of $2 \mathrm{~h}$ duration gives the desired error of $1 \mathrm{~cm}$ of water. After $8 \mathrm{~h}$ the error is $0.5 \mathrm{~cm}$ of water, and after $24 \mathrm{~h}$ it is $0.3 \mathrm{~cm}$ of water. At an altitude of $2000 \mathrm{~m}$ at which most avalanches are released, the count rate is doubled and the measuring error is 0.7 of that at sea-level. At an altitude of $3000 \mathrm{~m}$ the count rate is four times that at sea-level. In other regions at other latitudes and elevations other values would be found.

The necessary equipment can be built into the ground in autumn so that the surface is level with the ground. A slot antenna of frequency around $400 \mathrm{MHz}$ is used for transmission of the data.

* Dr W Fritzsche died before submitting the full text of his paper. 